\title{
Renal tubular and papillary necrosis after dehydration in infancy
}

\author{
ANN BANISTER and G. W. HATCHER* \\ From the Department of Child Health, Alder Hey Children's Hospital, Liverpool
}

\begin{abstract}
Banister, A., and Hatcher, G. W. (1973). Archives of Disease in Childhood, 48, 36. Renal tubular and papillary necrosis after dehydration in infancy. Two infants are described who developed renal tubular and papillary necrosis. In one, severe problems of management occurred during the diuretic phase. In the other, the intravenous pyelogram showed characteristic changes during the acute illness. The urinary findings are compared with those in other dehydrated infants and a means of early diagnosis is suggested. In a dehydrated infant an initial urine sodium of more than $100 \mathrm{mEq} / 1$., the persistence of osmolality below $500 \mathrm{mOsm} / \mathrm{kg}$, and urea below $1500 \mathrm{mg} / 100 \mathrm{ml}$ suggest renal tubular damage.
\end{abstract}

In 1970 Chrispin et al. reported three young infants who developed renal tubular and papillary necrosis after dehydration due to gastroenteritis. The distinctive appearance of the intravenous pyelogram made diagnosis possible during the acute illness. Two further cases are presented.

\section{Case reports}

Case 1. This previously healthy 3-month-old girl was admitted severely dehydrated, weight $3.65 \mathrm{~kg}$, with acidotic breathing and circulatory failure after two days of diarrhoea and vomiting. Serum sodium was $152 \mathrm{mEq} / 1$., potassium $6 \mathrm{mEq} / 1$., chloride 131 $\mathrm{mEq} / \mathrm{l}$., standard bicarbonate $10 \mathrm{mEq} / 1$., and blood urea $170 \mathrm{mg} / 100 \mathrm{ml}$. Urine was passed 4 hours after intravenous fluids were started. It was sterile, contained protein and a few red cells, and was unusually dilute. She continued to pass large quantities of dilute urine with a high sodium and chloride and low potassium and urea content, even in the presence of dehydration, hyponatraemia, and hyperkalaemia. From 24 to 36 hours the urine was tinged with blood.

Fig. 1 shows details of her course in the first 5 weeks of treatment. Initially it was very difficult to control her fluid and electrolyte status. Episodes of dehydration or hyponatraemia and peripheral circulatory failure occurred, with hypernatraemia occurring on one occasion when too much sodium was given. Throughout this period she did not gain weight. Little alteration of osmolality, sodium, potassium, or urea content of the urine occurred despite wide fluctuations in the plasma levels, suggesting loss of renal homeostatic control. Fig. 2 shows that only limited conservation of sodium was possible with

Received 22 May 1972.

*Present address: Royal Alexandra Hospital for Sick Children, Brighton. hyponatraemia, the minimum urine concentration being $c$ $52 \mathrm{mEq} / \mathrm{l}$. Titratable acid and ammonia concentrations were low.

She was eventually stabilized on $1200 \mathrm{ml}$ fluid and $30 \mathrm{mEq}$ sodium per day, twice the normal fluid and $\vec{\omega}$ three times the normal sodium requirement, given firg $\omega$ as intravenous and later as oral supplements to he्य

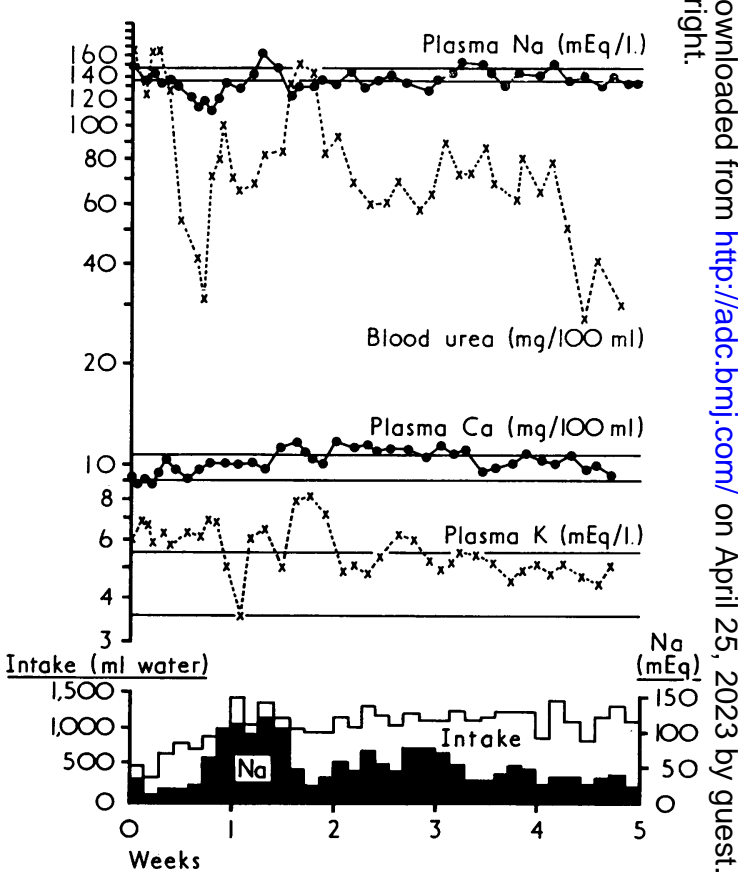

FIG. 1.-Case 1. Course over first 5 weeks of illness. 


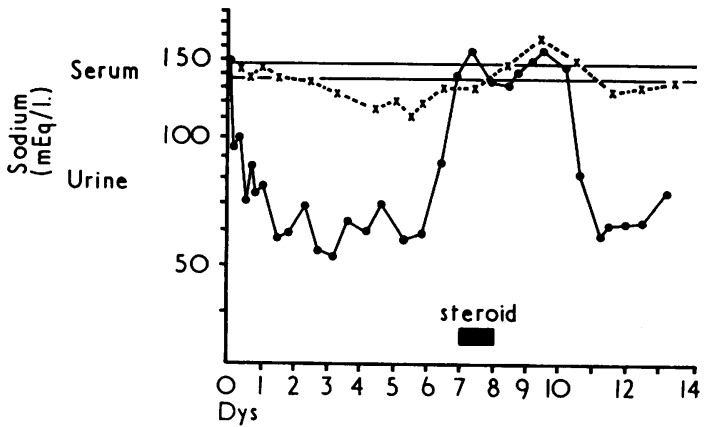

FIG. 2.-Case 1. Serum and urine sodium in first 2 weeks.

normal milk feeds. No extra potassium was needed. The blood pressure remained normal. After 6 weeks extra water and salt were gradually tailed off, and she continued to thrive without them. The persistent salt-losing state with hyperkalaemia suggested adrenal insufficiency, and on the seventh day from admission $0.25 \mathrm{mg}$ aldosterone i.m. and two oral doses of $0.1 \mathrm{mg}$ 9 - $\alpha$-fludrocortisone were given. This had no effect on the urinary output of sodium (Fig. 2) or potassium, showing a lack of tubular response to salt-retaining steroids. Urinary 17-hydroxy- and ketosteroid excretion on the fifth day were normal.

A standard intravenous pyelogram was performed on day 15. Neither kidney was well seen, but urinary obstruction could be excluded. We then read the report of Chrispin et al. (1970) and IVP was repeated on day 28 , with films taken up to one hour after injection of $15 \mathrm{ml}$ diatrizoic acid. No persistent opacification of the kidney was seen at this stage. An IVP four months after the illness showed extensive papillary necrosis (Fig. 3).

Renal biopsy was performed four weeks after admission (Fig. 4). There was patchy calcification within

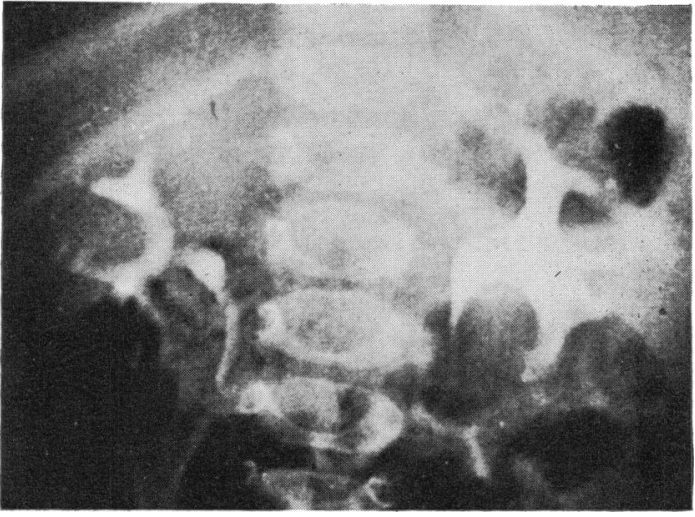

FIG. 3.-Case 1. IVP four months after illness, showing deformity of the calyces of both kidneys, with the tips of several papillae separated and outlined by contrast medium.

tubules, some of which were lined with degenerate epithelium and others with flattened regenerating epithelium. The presence of such marked calcification led to a review of the serum calcium levels (Fig. 1). No excess vitamin $D$ had been given. A calcium load test (Barr and Forfar, 1969) was abnormal showing the pattern of mild hypercalcaemia. It remains uncertain whether this mild tendency to hypercalcaemia contributed to the renal damage, resulted in some way from it, or was coincidental.

She has since been on a low calcium diet and is thriving, with a normal serum calcium and blood urea. A calcium load test at 1 year of age remains abnormal. Renal concentrating and acidifying powers have improved but are still abnormal. After 24 hours of concentrated milk, urine osmolality was $455 \mathrm{mOsm} / \mathrm{kg}$ at $5 \frac{1}{2}$ months of age and $638 \mathrm{mOsm} / \mathrm{kg}$ at 1 year. After a

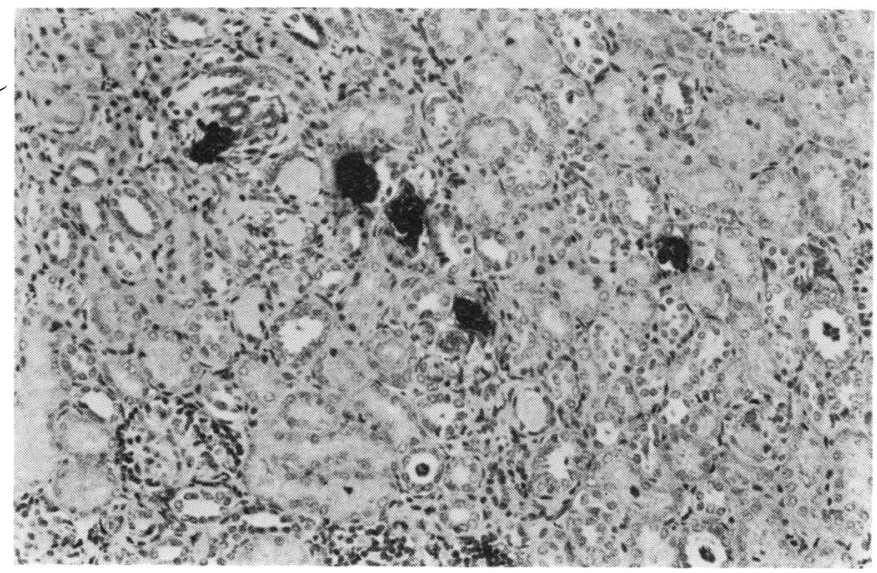

Fig. 4.-Case 1. Von Kossa, low power view of renal biopsy. Several areas of calcification are seen within abnormal tubules. 
standard ammonium chloride load she excreted $6 \mu \mathrm{Eq}$ ammonia/min per $1.73 \mathrm{~m}^{2}$ at 11 weeks of age and 15 $\mu \mathrm{Eq}$ at $8 \frac{1}{2}$ months.

Case 2. This baby girl aged 12 weeks was admitted severely dehydrated and in circulatory failure with a history of a few hours of diarrhoea and anorexia. She was born at term, weighing $2.3 \mathrm{~kg}$, with an imperforate anus and rectoperineal fistula which were repaired on the third day of life. With regular anal dilatation at home she progressed satisfactorily until this illness. IVP and urine examination previously had been normal. 5 minutes after reaching the ward she had a cardiac arrest. 36 hours later cardiac arrhythmias were followed by two further arrests.

After initial resuscitation, the serum sodium was $158 \mathrm{mEq} / 1$., chloride $110 \mathrm{mEq} / 1$, , potassium $8.1 \mathrm{mEq} / 1$., and urea $215 \mathrm{mg} / 100 \mathrm{ml}$. The blood urea fell slowly to around $100 \mathrm{mg} / 100 \mathrm{ml}$ from day 5 , and serum sodium fell to range between 118 and $131 \mathrm{mEq} / 1$; she did not gain weight. When extra fluid and salt were given as $0.45 \%$ saline by nasogastric tube between milk feeds, serum sodium and blood urea returned to normal and her general condition improved for a while. No extra potassium was needed. However, she remained unresponsive, stiff, and unable to suck, and had frequent generalized convulsions until her death 4 weeks after admission.

Urine was passed 12 hours after admission. It contained protein, a few red cells, and was unusually dilute. During the 2 days of urine collection she continued to pass dilute urine with a high sodium and low urea content. Titratable acid and ammonia concentrations were low. She also had a high serum calcium 2 weeks after admission, ranging from 10.8 to $11 \cdot 3$ $\mathrm{mg} / 100 \mathrm{ml}$, but she was too ill for a calcium load test to be done. IVP was performed on the tenth day with films taken up to one hour (Fig. 5). A week after admission urine showed infection with Esch. coli, and it is felt this may have been present from the start and the cause of her severe illness.

At necropsy extensive cerebral venous thrombosis was found with shrinkage of the cerebral hemispheres. Both kidneys showed necrosis of several papillae, with loss of the tip in some. The cortex showed patchy degeneration of tubules and calcification, appearances similar to those shown in Fig. 4. There was acute pyelonephritis.

\section{Findings in other dehydrated infants}

Urine was studied during the first few days of illness in 30 infants with hypernatraemic dehydration of comparable severity to the two with renal damage. The average age was $9 \frac{1}{2}$ weeks (range 1-52) and average blood urea $203 \mathrm{mg} / 100 \mathrm{ml}$ (range 88-450). In the 18 where acid excretion was measured the mean plasma standard bicarbonate was $11 \mathrm{mEq} / \mathrm{l}$. (range 5-19). 16 were thought to be in circulatory failure and required urgent resuscitation with intravenous plasma. The main cause of dehydration was gastroenteritis in 24 and respiratory infection in 6 . None had evidence of renal damage or urinary infection and none had received excessive salt or solute. The results are shown in the Table. 29 infants with milder dehydration were also studied and the findings are mentioned where appropriate.

Many dehydrated infants showed poor initial osmolaf and urea concentration (osmolality measured witbo Fiske Osmometer), but both tended to rise during treatment, to fall again with full hydration and the onset of a diuresis. This rise was not seen in infants with

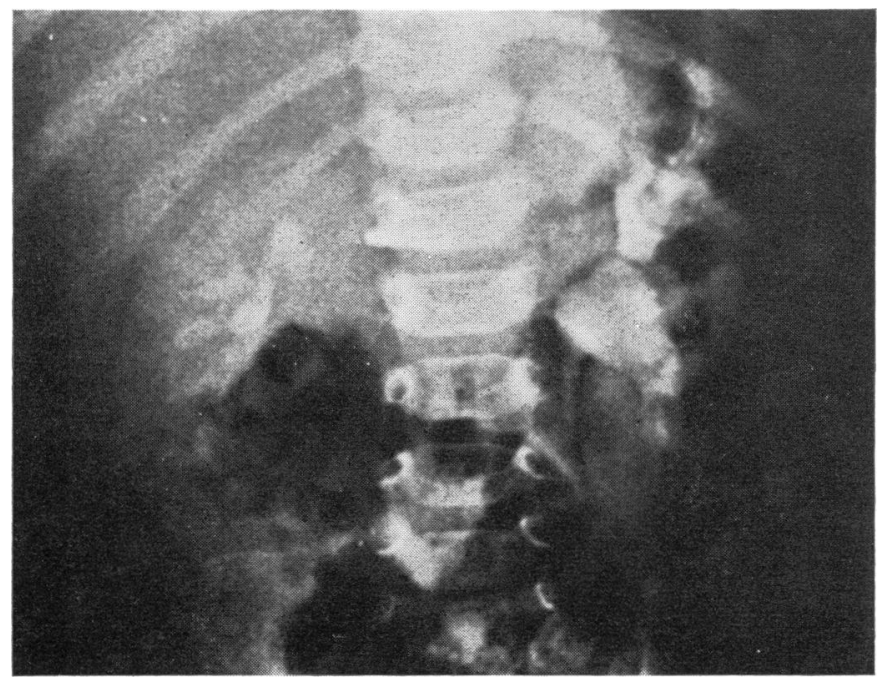

FIG. 5.-Case 2. IVP on tenth day of illness. Film at 1 hour, showing opacification of both kidneys with marked density of the renal pyramids, best seen in the right kidney. 
TABLE

Urine results in infants with hypernatraemic dehydration compared with 2 infants with renal tubular necrosis

\begin{tabular}{|c|c|c|c|c|}
\hline & No. & Average (range) & Case 1 & Case 2 \\
\hline $\begin{array}{l}\text { Time first urine (hr) } \\
\text { Osmolality first urine (mOsm/kg) } \\
\text { Maximum osmolality in illness } \\
\text { Sodium first urine (mEq/l.) } \\
\text { Urea first urine (mg/100 ml) } \\
\text { Maximum urea in illness } \\
\text { Urea urine/plasma first urine } \\
\text { Maximum urea uri ce/plasma } \\
\text { Titratable acidity first urine (mEq/l.) } \\
\text { Ammonia first urine (mEq/l.) } \\
\text { Heavy proteinuria } \\
\text { Haematuria }\end{array}$ & $\begin{array}{l}30 \\
28 \\
30 \\
29 \\
22 \\
23 \\
22 \\
23 \\
18 \\
18 \\
27 \\
27\end{array}$ & $\begin{array}{l}5 \cdot 9(1-14) \\
714(493-1153) \\
816(532-1188) \\
43 \cdot 2(4-142) \\
1820(330-4000) \\
2725(1500-4700) \\
12 \cdot 1(0 \cdot 8-34 \cdot 6) \\
26 \cdot 2(4 \cdot 3-51 \cdot 6) \\
50 \cdot 5(22-90) \\
77(20-194) \\
12+\text { ve } \\
3+\text { ve }\end{array}$ & $\begin{array}{r}4 \\
408 \\
420 \\
142 \\
1300 \\
1420 \\
9 \cdot 2 \\
10 \cdot 8 \\
2 \cdot 5 \\
12 \cdot 5 \\
+ \text { ve } \\
+ \text { ve }\end{array}$ & $\begin{array}{r}12 \\
409 \\
409 \\
128 \\
500 \\
990 \\
2 \\
4 \cdot 1 \\
4 \cdot 3 \\
20 \cdot 4 \\
+ \text { ve } \\
+ \text { ve }\end{array}$ \\
\hline
\end{tabular}

renal damage, where urine osmolality and urea content remained low and were both well below the range of normal infants. The ratio of urinary urea to plasma urea concentration $(\mathrm{U} / \mathrm{P})$ was less than 10 in the first urines of 15 of 22 infants with normal kidneys. It rose during treatment to 14 or more in all but one case. With full hydration several infants showed a subsequent fall below 10. A few of the mildly dehydrated infants also showed an initial U/P below 10 .

Both infants with renal damage had a high sodium in the first urine passed; only one normal infant had a sodium as high. Infants studied with normonatraemic dehydration have shown lower initial urinary sodium concentrations than the hypernatraemic. Age had an effect on the urine sodium whatever the plasma sodium level. The three normal infants with an initial urine sodium greater than $100 \mathrm{mEq} / \mathrm{l}$. were all less than 6 weeks old, and those with an initial urine sodium greater than $35 \mathrm{mEq} / 1$. were all less than 3 months old. With dehydration due to sodium overload there may be a high urine sodium, but osmolality will also be high. Urinary sodium tended to rise during rehydration in infants with normal kidneys, the increase being most marked in those receiving the most sodium in treatment.

Titratable acid and ammonia concentrations were low in first and subsequent urines in the infants with renal damage (method according to Kildeberg, 1968). Despite varying degrees of correction with sodium bicarbonate, all the acidotic babies with normal kidneys produced greater concentrations of titratable acid. Initial ammonia concentration was high and rose higher in later urines.

\section{Discussion}

The diagnosis of renal tubular and papillary necrosis in infancy is usually made post mortem. Mauer and Nogrady (1969) described the clinical course and late IVP findings in an asphyxiated newborn baby who developed papillary necrosis and survived. Chrispin et al. (1970) reported prolonged opacification of the kidneys with increased density of the renal pyramids during IVP in three infants who had evidence of renal tubular and papillary necrosis and recovered. Experiments with rats (Risdon, Berry, and Chrispin, 1970) showed similar radiological changes in renal medullary necrosis; tubular necrosis alone produced prolonged renal opacification without increased density of the pyramids. Case 2 showed the same changes as Chrispin's infants on the tenth day of the illness, and tubular and papillary necrosis were confirmed post mortem. Case 1 probably had both lesions, but did not show these radiological abnormalities at 4 weeks.

The common factor in all five older infants was severe dehydration, though our second baby also had several circulatory arrests, and urinary infection may have contributed to the renal damage. Hypernatraemia may be a contributing factor in renal tubular damage (Rush et al., 1961). As salt-retaining steroids did not alter the urine electrolytes, it is likely that the prolonged hyperkalaemia in Case 1 was due to damage and unresponsiveness of the distal tubules. Reports of the diuretic phase of renal damage stress excessive losses of both sodium and potassium. Neither of our two infants showed abnormal potassium loss, and Case 1 had a low potassium output during the period of hyperkalaemia.

In view of the life-threatening salt and water losing state which may occur and the potential for recovery, early diagnosis of renal tubular necrosis would be valuable. Kerr (1968) stresses that the period of oliguria in acute renal failure is shorter in children than adults, and suggests that a urinary sodium less than $30 \mathrm{mEq} / \mathrm{l}$. and urea greater than $1000 \mathrm{mg} / 100 \mathrm{ml}$ would be against the diagnosis of renal necrosis, while proteinuria greater than $30 \mathrm{mg} / 100 \mathrm{ml}$, casts, and red and white cells would support it. James (1968) states the $U / P$ urea is above 40 in prerenal failure and about 10 in true renal failure. Our findings show that some 
modification of these statements is needed in young infants, especially if they are dehydrated.

The period of anuria may be very short. Heavy proteinuria is not unusual in dehydrated infants, and though haematuria suggests renal damage it may occur with normal kidneys. Dehydrated infants, especially if hypernatraemic and very young, may pass urine with a high sodium concentration in early samples, but an initial sodium above 100 $\mathrm{mEq} / \mathrm{l}$. would suggest renal damage unless salt overload had occurred. Later urinary sodium will depend on sodium deficit and the treatment given. However, in our experience, with a serum sodium less than $135 \mathrm{mEq} / \mathrm{l}$. urine sodium will be below $20 \mathrm{mEq} / \mathrm{l}$. unless potassium deficiency is present. Though osmolality and urea may be low in initial samples, probably because of a low glomerular filtration rate, osmolality should rise above $500 \mathrm{mOsm} / \mathrm{kg}$ during rehydration, and urea above $1500 \mathrm{mg} / 100 \mathrm{ml}$ if the kidneys are normal. The U/P urea should rise above 13 during treatment. Titratable acid and ammonia concentrations also show a clear difference from normal in infants with renal damage.

The interpretation of a single urine examination will depend on the state of hydration and sodium balance, and serial measurements give more useful information. Titratable acidity and ammonia are not easily measured routinely, but the other laboratory methods are quick and easily combined with the usual estimation of serum electrolytes and urea. Not all centres will have an osmometer. Specific gravity could be used, but is less discriminating than osmolality, especially as transient glycosuria is common in hypernatraemic infants. Urine from severely dehydrated or collapsed infants can be refrigerated for a few days and is then available for analysis if renal damage is suspected from the clinical course.

Our experience has confirmed the value of IVP in the diagnosis of renal tubular necrosis within the first three weeks, and also suggests that measurement of the osmolality of the first urine obtained from a severely dehydrated infant is a useful screening test. If it is less than $500 \mathrm{mOsm} / \mathrm{kg}$, sodium, urea, and osmolality should be measured in the first urines passed. The combination of persistently low urine osmolality and urea and a high initial sodium content would make renal tubular necrosis a strong possibility.

We are grateful to Professor D. Hull for helpful advice, to Dr. E. G. Hall for pathological details, and Dr. C. Davies for the radiological reports.

\section{REFERENCES}

Barr, D. G. D., and Forfar, J. O. (1969). Oral calcium-loading test in infancy with particular reference to idiopathic hypercalcaemia. British Medical fournal, 1, 477.

Chrispin, A. R., Hull, D., Lillie, J. G., and Risdon, R. A. (1970) Renal tubular necrosis and papillary necrosis after gastroenteritis in infants. British Medical fournal, 1, 410.

James, J. A. (1968). Renal Disease in Childhood, p. 254. Mosby, St. Louis.

Kerr, D. N. S. (1968). Paediatric Urology, p. 117. Ed. by D. I. Williams. Butterworths, London.

Kildeberg, P. (1968). Clinical Acid-Base Physiology. Williams and Wilkins, Baltimore.

Mauer, S. M., and Nogrady, M. B. (1969). Renal papillary and cortical necrosis in a newborn infant: report of a survivor with roentgenologic documentation. Fournal of Pediatrics, 74, 75

Risdon, R. A., Berry, C. L., and Chrispin, A. R. (1970). Urographe changes in acute papillary necrosis in the rat. British Medicat fournal, 3, 263.

Rush, B. F., Finberg, L., Daviglus, G. F., and Cheung, C. (1961). Pathologic lesions in experimental hypernatremia induced by extracorporeal dialysis. Surgery, 50, 359.

Correspondence to Dr. A. Banister, Department of Child Health, Alder Hey Children's Hospital, Liverpool L12 2AP. 